\title{
Recovery time and associated factors of severe acute malnutrition among children in Bahir Dar city, Northwest Ethiopia: an institution based retrospective cohort study
}

Degnet Teferi Asres ${ }^{1 *}$, Reddy P. C. J. Prasad ${ }^{1}$ and Tadesse Awoke Ayele ${ }^{2}$

\begin{abstract}
Background: Malnutrition commonly affects all groups in a community, but infants and young children are the most vulnerable. Worldwide, nearly 24 million under five children experience severe acute malnutrition (SAM) which contributes to one million child deaths yearly and 19 million severely wasted children are living in developing countries. While the treatment of severe acute malnutrition (SAM) is well established, achieving desired outcomes has proven to be challenging. There is limited evidence showing the success of treatments in the study area. Therefore, this study aimed to determine recovery time from severe acute malnutrition and identify predictors among children of 6-59 months of age.

Methods: Facility based retrospective cohort study was conducted among 401 children 6-59 months of age who have been treated for SAM. Both descriptive and analytic analyses were executed. The results were determined using KaplanMeier procedure, log-rank test and Cox-regression. Variables having $P$-value $\leq 0.2$ during binary analysis were entered into multivariate analysis. $P$ value $<0.05$ was considered as statistically significant.

Results: The recovery rate was $51.9 \%$ and the median recovery time was 16 days ( $95 \% \mathrm{Cl}$ : $14.233-17.767)$. Controlling for other factors; having anemia at admission, no plumpy nut provision, failing to enter in to phase 2 on day 10 and a weight gain of more than $8 \mathrm{~g} / \mathrm{kg} /$ day were significant predictors of recovery time.

Conclusions: Nutritional recovery rate was far outside of the accepted minimum international standard while median recovery time ranged in the accepted minimum international standard. Children had a lower chance of recovering early when they had anemia at admission, not provided plumpy nut, failed to enter phase 2 on day 10 and failed to gain more than $8 \mathrm{~g} / \mathrm{kg} /$ day. Therefore, efforts should be strengthened to facilitate early recovery of children by considering the identified predictors of recovery time.
\end{abstract}

Keywords: Severe acute malnutrition, Treatment outcomes, Recovery time, Northwest Ethiopia

\section{Background}

Malnutrition can be defined as a state of nutrition in which deficiency or excess of energy, protein, and other nutrients causes measurable adverse effects [1]. Although uncommon in developed countries, malnutrition in children remains major public health problem in many developing countries [2]. It continues to be the most important risk factor for growth retardation, illness

\footnotetext{
* Correspondence: degnet2006@gmail.com

${ }^{1}$ Department of Applied Human Nutrition, Bahir Dar Institute of Technology, Bahir Dar University, Bahir Dar, Ethiopia

Full list of author information is available at the end of the article
}

and death with huge masses of young children particularly affected [3].

Malnutrition can be of the acute, chronic or mixed type [1]. Severe Acute Malnutrition (SAM) is one form of acute malnutrition which refers to weight for height ratio of less than -3 standard deviations or weight for height ratio of below 70\% or Mid Upper Arm Circumference (MUAC) < $110 \mathrm{~mm}$ or presence of nutritional edema [4].

Today, 52 million (about 8.3\%) children under five in the world are suffering from acute malnutrition. Off those children affected, the majority $(>90 \%)$ are found in South and Southeast Asia and sub-Saharan Africa.

(c) The Author(s). 2018 Open Access This article is distributed under the terms of the Creative Commons Attribution 4.0 International License (http://creativecommons.org/licenses/by/4.0/), which permits unrestricted use, distribution, and 
Despite to communal belief, acute malnutrition (also known as wasting) does not occur only in emergency conditions, it is also common in stable settings in countries like India, Indonesia, Kenya and Ethiopia [5].

Till now, acute malnutrition was also perceived as a condition of humanitarian emergencies rather than a development and public health importance [5]. This is in the face of the long-term economic and social costs associated with the condition. But currently, more attention is started to be given to the problem and recognized as public health and development agenda [5].

While there is a well-established and evidence-based management protocol for treatment of SAM [6, 7], integrating it into essential health packages and achieving desired outcomes has proven to be challenging. This might be due to weaknesses in health systems and challenges in availability of treatment commodities at local levels [8]. Generally, effective management of SAM remains as a huge challenge in low resource healthcare settings [2].

Ethiopia, particularly the study area is not an exception in this regard and the successes of treatment outcomes of SAM in healthcare settings should be tested. However, there are only limited studies on this topic in the country and there was no any study particularly in the study area. The aim of this study was therefore, to determine recovery time from SAM and identify predictors of recovery time among children of 6-59 months of age using the inpatient program at Felegehiwot referral hospital, Bahir Dar city administration, Northwest Ethiopia.

\section{Methods}

\section{Study area and period}

Institution based retrospective cohort study was conducted from March to April, 2016. The study was conducted at Felegehiwot referral hospital which provides inpatient services for the management of SAM in Bahir Dar city administration. Bahir Dar is a capital city of Amhara region and located $565 \mathrm{kms}$ from Addis Ababa, North west Ethiopia. The projected population number in 2012 was estimated to be 252,256 of whom 131,930 were females (2011 annual report of Bahir Dar special zone, unpublished). There are 10 government health centers and one government referral hospital in the city administration. There are also private health facilities. Currently, Felegehiwot referral hospital is the only health facility which provides inpatient services for the management of SAM in Bahir Dar city administration.

\section{Sample size and sampling procedure}

All children 6-59 months of age with SAM that have been admitted and treated at therapeutic feeding unit (TFU) of the hospital from October 2012 to April 2016 were eligible for the study. Those children with SAM who did not have proper records (incomplete records/ missing) were excluded from the study. Similarly, children with documented secondary undernutrition due to other pathological disorders and with other causes of edema were also excluded from the study. Using Epi info version 6 (CDC, Atlanta) StatCalc programs the sample size was estimated to be 401 . Systematic sampling procedure was used to select cases and all cases of SAM were obtained from TFU register book and client cards enrolled from October 1, 2012 to April 30, 2016.

\section{Operational definitions}

Recovery time - number of days it takes from admission until a child is recovered from SAM.

Recovered-are those children who have become free from medical complications, edema and have achieved and maintained sufficient weight gain (when they reach $85 \%$ weight for length) [9].

Readmission- SAM cases that are declared cured or recovered but relapsed to be admitted (returned back for treatment).

Default- SAM cases that are against (care givers sign on behalf of their child to leave the treatment before the child is cured) or SAM cases that are lost with unknown status.

Phase 2- children are transferred in to phase 2 when they regain good appetite and lose their edema or at least reduced to ++ or $+[9]$.

Data collection procedures and quality control measures A structured data abstraction form was used for data collection. Data were gathered for baseline characteristics, routine medications, supplements and therapeutic feedings, follow-up characteristics and outcome status. During data collection, two clinical nurses as data collectors and one public health expert as a supervisor were recruited and $2 \mathrm{~d}$ intensive training was given. The data abstraction form was adopted from Ethiopian protocol for the management of severe acute malnutrition [9] and the sphere standard for management of severe acute malnutrition [10].

\section{Data processing and analysis}

Data were entered in to Epi info version 6 statistical software and then exported to SPSS version 20 (IBM, USA) for analysis. Cross tabulation, graph and frequency tables were used to report the descriptive data. Recovery time from SAM was estimated using Kaplan-Meier procedure. Log rank test was used to test whether the observed difference of recovery time between different groups of predictor variables is significant or not. Multivariate Cox proportional hazard regression analysis was carried out to identify predictor variables. Variables having a $P$-value $\leq 0.2$ during binary variable Cox proportional hazard regression analysis were entered into multivariate analysis. $P$ value $<0.05$ was considered as statistically significant. Both Crude Hazard Ratio (CHR) and Adjusted Hazard 
Ratio (AHR) with 95\% confidence interval (CI) were used to show the strength of association.

\section{Results \\ Sociodemographic and baseline characteristics of children at admission}

Out of the total 401 children in the cohort; 195 (48.6\%) were males and 206 (51.4\%) were females. Majority of study subjects $(79.3 \%)$ were rural residents. From all cohorts; $95.5 \%$ were newly admitted, $40.6 \%$ were edematous whereas $56.1 \%$ of children were wasted. For almost all children (96.3\%) it was not documented whether children passed or failed the appetite test (Table 1).

\section{Routine medications}

Of all children, more than half (54.6\%) received amoxicillin, 67.6\% received Ampicilin/gentamicin, $72.8 \%$ received measles and only $23.4 \%$ of children received de-worming (Table 2).

\section{Supplements and therapeutic feedings}

Out of the 401 children; the majority (82.5\%) received folic acid supplement, more than half $(58.1 \%)$ took vitamin A supplement, almost all (96.0\%) received a therapeutic food (F-75) and more than half (54.4\%) received plumpy nut. However, it is only $21.2 \%$ of children received iron supplement (Table 3).

\section{Follow up characteristics}

From 163 children with edema, 20.2\% fail to start to lose edema on day 4 . One hundred twenty-nine children out of 401 (32.2\%) fail to enter in to phase 2 on day 10 and among edematous children for $16.3 \%$ of them edema was still present on day 10 . Out of total children included for this study, $13.2 \%$ failed to gain more than $8 \mathrm{~g} / \mathrm{kg} /$ day during phase 2 and $10.5 \%$ suffered heart failure (Table 4).

\section{Treatment outcomes}

Out of the total 401 children in the cohort; 208 (51.9\%) were recovered, 17 (4.2\%) died, 143 (35.7\%) defaulted, 6(1.5\%) not responded and 27 (6.7\%) transferred (Table 5). The nutritional recovery rate was 2.27 (95\% CI: $1.55-3.43)$ per 100-person day observations among entire subjects in the cohort. The median nutritional recovery time was estimated to be 16 days (IQR: $95 \% \mathrm{CI}$; 14.233-17.767) (Fig. 1).

Predictors of recovery time from severe acute malnutrition There was a significant difference in the median recovery time between different groups of predictor variables. The median nutritional recovery time for children who had cough at admission was 17 days (95\% CI: 14.8-19.2) while it was 15 days (95\% CI: 13.3-16.7) for those who didn't have. Similarly, for children who were HIV positive at admission the median recovery time was 27 days (95\% CI: 12.8-41.2) compared to HIV negative which was 17 days (95\% CI: 14.1-19.9). The highest difference in median recovery time was observed between children who received plumy nut and those who didn't, which was 14 days (95\%CI: 13.033-14.967) and 28 days (95\%CI: 23.301-32.699) respectively (Table 6).

Twenty-eight independent variables were analyzed in the Cox proportional hazard regression analysis with the dependent variable. Twelve were significantly associated with recovery time from SAM in the binary Cox proportional hazard regression and 13 variables which have a $p \leq 0.2$ were entered in to a multiple Cox proportional hazard regression analysis. However, only four variables; being anemic at admission, provision of plumpy nut throughout the treatment, fail to enter in to phase 2 on day 10 and mean weight gain had significant association with the dependent variable. Children who had no anemia at admission were 1.6 times $(\mathrm{AHR}=1.552$; $95 \%$ CI: $1.134,2.124)$ more likely to recover earlier compared to those who had. Children who received plumpy nut during their treatment were 2 times $(\mathrm{AHR}=2.063$; 95\%CI: $1.356,3.139$ ) more likely to recover earlier compared to their counterparts. Similarly, children who entered phase 2 on day 10 were about 3 times $(\mathrm{AHR}=2$. 938; 95\%CI: 1.635-5.279) more likely to recover in shorter days compared to those who failed to enter. Children who gained on average more than $8 \mathrm{~g} / \mathrm{kg} /$ day were 1.2 times (AHR $=1.200$; 95\%CI: $1.014-1.422$ ) more likely to recover earlier compared to those who gained less than $8 \mathrm{~g} / \mathrm{kg} /$ day (Table 7).

\section{Discussion}

In this study, the overall recovery time from SAM and differences of recovery time between different groups of children were estimated. The association between recovery time from SAM and independent predictors was also assessed.

Accordingly, the median nutritional recovery times was estimated to be 16 days (95\%CI: $14.233-17.767)$ and it was within the acceptable maximum international standards set at $<28$ days $[10,11]$. This finding was consistent with other institution-based study in Mekelle, Ethiopia which reported 17 days [12]. However, it was higher than the study done in Zambia that reported 13 days [13]. This might be related to differences in treatment and caring practices, health care settings and other socioeconomic factors among the study areas. Studies indicated that it is only by complying with the standard protocol for management of SAM that better program outcomes could be assured [14].

However, the median nutritional recovery time was lowest compared to the study reports from Kamba 
Table 1 Sociodemographic and baseline characteristics of children with severe acute malnutrition, Bahir Dar, Northwest Ethiopia; October, 2012 to April, 2016

\begin{tabular}{|c|c|c|c|}
\hline Variables & & Frequency & Percent \\
\hline \multirow[t]{2}{*}{ Sex of child } & Male & 195 & 48.6 \\
\hline & Female & 206 & 51.4 \\
\hline \multirow[t]{2}{*}{ Residence } & Urban & 83 & 20.7 \\
\hline & Rural & 318 & 79.3 \\
\hline \multirow[t]{2}{*}{ Age of child } & $6-23$ & 221 & 55.1 \\
\hline & $24-59$ & 180 & 44.9 \\
\hline \multirow[t]{3}{*}{ Admission status } & New & 383 & 95.5 \\
\hline & Return from default & 2 & .5 \\
\hline & Readmission & 16 & 4.0 \\
\hline \multirow[t]{3}{*}{ Diagnosis at admission } & Edematous & 163 & 40.6 \\
\hline & Wasted & 225 & 56.1 \\
\hline & Both & 13 & 3.2 \\
\hline \multirow[t]{3}{*}{ Breastfeeding history } & Yes & 362 & 90.3 \\
\hline & No & 38 & 9.5 \\
\hline & Not documented & 1 & .2 \\
\hline \multirow[t]{2}{*}{ Diarrhea } & Yes & 211 & 52.6 \\
\hline & No & 190 & 47.4 \\
\hline \multirow[t]{2}{*}{ Vomiting } & Yes & 219 & 54.6 \\
\hline & No & 182 & 45.4 \\
\hline \multirow[t]{2}{*}{ Cough } & Yes & 205 & 51.1 \\
\hline & No & 196 & 48.9 \\
\hline \multirow[t]{3}{*}{ Fever } & Yes & 260 & 64.8 \\
\hline & No & 140 & 34.9 \\
\hline & Not documented & 1 & .2 \\
\hline \multirow[t]{3}{*}{ HIV } & Yes & 21 & 5.2 \\
\hline & No & 155 & 38.7 \\
\hline & Not documented & 225 & 56.1 \\
\hline \multirow[t]{3}{*}{ Malaria } & Yes & 15 & 3.7 \\
\hline & No & 382 & 95.3 \\
\hline & Not documented & 4 & 1.0 \\
\hline \multirow[t]{2}{*}{ Pneumonia } & Yes & 116 & 28.9 \\
\hline & No & 285 & 71.1 \\
\hline \multirow[t]{3}{*}{ TB } & Yes & 38 & 9.5 \\
\hline & No & 360 & 89.8 \\
\hline & Not documented & 3 & .7 \\
\hline \multirow[t]{3}{*}{ Anemia } & Yes & 260 & 64.8 \\
\hline & No & 140 & 34.9 \\
\hline & Not documented & 1 & .2 \\
\hline \multirow[t]{2}{*}{ Open skin lesions } & Yes & 70 & 17.5 \\
\hline & No & 331 & 82.5 \\
\hline \multirow[t]{2}{*}{ Fever $>39^{\circ} \mathrm{C}$} & Yes & 45 & 11.2 \\
\hline & No & 356 & 88.8 \\
\hline
\end{tabular}

District, South West Ethiopia that indicated recovery time of 50 days [15] and Karat and Fasha stabilization Centers, Southern Ethiopia that reported 26 days [16].

Further analysis comparing the median recovery time between different groups of predictor variables showed that there were significant differences in median nutritional recovery time between children with SAM who had cough at admission and those who didn't have; children with human immunodeficiency virus (HIV) and without HIV and who had tuberculosis (TB) and those who didn't have. Likewise, there were significant difference in the median recovery time with regard to variables like presence of anemia, fever $>39{ }^{\circ} \mathrm{C}$, provision of plumpy nut, fail to regain appetite on day 4 , fail to lose edema on day 4 , edema still present on day 10 , fail to enter phase-2 on day 10, failure to gain more than $5 \mathrm{~g} /$ $\mathrm{kg} / \mathrm{d}$ for 3 successive days. The highest median recovery time difference was observed between children who received plumy nut and those who didn't which were 14 days and 28 days respectively.

But, significant differences in median recovery time were not observed between other groups of predictor variables including residence, sex, age, admission status, diagnosis at admission, diarrhea, breastfeeding history $(P$-Value $<0.05)$. For some predictor variables, this is in consistent with a study conducted in therapeutic feeding centers, Southern Ethiopia, where median recovery time was not significantly different for residence, sex, age [16].

Concerning predictors of recovery time from SAM; presence of anemia at admission, provision of plumpy nut, fail to enter in to phase- 2 on day 10 and mean weight gain at discharge had significant association with the dependent variable.

Children who had no anemia at admission were 1.6 times $(\mathrm{AHR}=1.552 ; 95 \% \mathrm{CI}: 1.134,2.124)$ more likely to recover earlier compared to those who had. However, a study in Burkina Faso indicated that with a strong respect of current inpatient SAM management, anemia did not have negative impact on nutritional recovery during hospitalization [17] which means even though children are anemic at admission if treated according to the protocol for management of SAM, it doesn't have negative effect on a nutritional recovery time. For this study, the reason might be due to the fact that children were not receiving iron supplement even when they 
Table 2 Provision of routine medications for children with severe acute malnutrition, Bahir Dar, Northwest Ethiopia; October, 2012 to April, 2016

\begin{tabular}{ll}
\hline Variables & Frequency (\%) \\
\hline Amoxicillin & $219(54.6)$ \\
Ampicilin/Gentamicin & $271(67.6)$ \\
Deworming & $94(23.4)$ \\
Measles vaccine & $292(72.8)$ \\
\hline
\end{tabular}

were anemic. It is because the finding indicated that while $64.8 \%$ of severely malnourished children were anemic, it is only $21.2 \%$ of the total children enrolled received iron supplement.

Children who received plumpy nut during their treatment were 2 times $(\mathrm{AHR}=2.063 ; 95 \% \mathrm{CI}: 1.356,3.139$ ) more likely to recover earlier compared to their counterparts. This is in line with a meta-analysis which included 14 studies in low and middle income settings and indicated that children in the ready to use therapeutic food group (RUTF) or plumy nut group were significantly more likely to recover and less likely to be non-responders [18]. According to that meta-analysis, children who received plumpy nut were 1.5 times more likely to recover than those receiving normal therapy. This might be due to the fact that children who received plumy nut might achieve rapid weight gain so that fulfilled the discharge criteria (as cured) early compared to those who didn't get the chance to consume plumpy nut [16]. A study carried out in Tigray, northern Ethiopia also indicated that plumpy nut had a positive effect to the recovery rate and revealed that as a child consumed one more sachet of plumpy nut, the recovery rate from SAM increased by $4 \%$ [14] and this might shorten the recovery time among those who received plumpy nut for this study.

Correspondingly, children who entered in to phase 2 on day 10 were about 3 times $(\mathrm{AHR}=2.938 ; 95 \% \mathrm{CI}$ : 1.635-5.279) more likely to recover in shorter days

Table 3 Provision of supplements and therapeutic feeding histories of children with severe acute malnutrition, Bahir Dar, Northwest Ethiopia; October, 2012 to April, 2016

\begin{tabular}{|c|c|c|}
\hline \multicolumn{2}{|c|}{ Variables } & Frequency (\%) \\
\hline \multicolumn{2}{|c|}{ Folic acid } & $331(82.5)$ \\
\hline \multicolumn{2}{|c|}{ Vitamin A } & 233(58.1) \\
\hline \multicolumn{2}{|c|}{$F-75$} & $385(96.0)$ \\
\hline \multicolumn{2}{|c|}{$F-100$} & 285(71.1) \\
\hline \multicolumn{2}{|c|}{ Plumpy nut } & 218(54.4) \\
\hline \multirow[t]{3}{*}{ Iron } & Yes & $85(21.2)$ \\
\hline & No & $314(78.3)$ \\
\hline & Not documented & $2(.5)$ \\
\hline
\end{tabular}

Table 4 Follow up characteristics of children with SAM, Bahir Dar, Northwest Ethiopia; October, 2012 to April, 2016

\begin{tabular}{ll}
\hline Variables & Frequency (\%) \\
\hline Fail to start to lose edema on day 4 & $33(20.2)$ \\
Edema still present on day 10 & $14(16.3)$ \\
Fail to enter in to phase 2 on day 10 & $129(32.2)$ \\
Fail to gain $>5 \mathrm{~g} / \mathrm{kg} / \mathrm{d}$ for 3 successive days & $145(36.2)$ \\
Heart failure & $42(10.5)$ \\
Weight gain $>8 \mathrm{~g} / \mathrm{kg} /$ day & $348(86.8)$ \\
\hline
\end{tabular}

compared to those who failed to enter. This might be due to the reason that unless children enter in to phase 2, they will not be given therapeutic foods (F-100 \& plumy nut) which can promote weight gain as rapid weight gain at stage one is dangerous. That is why F75 is formulated so that patients do not gain weight during this stage. In Phase-2; they are given plumpy nut or F100. Those formulas are designed for patients to rapidly gain weight (more than $8 \mathrm{~g} / \mathrm{kg} /$ day). Therefore, children who enter phase 2 early ( $\leq 10$ days) will enjoy this advantage and recover early compared to their counterparts [16].

Mean weight gain was also significantly associated with median recovery time by which children who gained more than $8 \mathrm{~g} / \mathrm{kg} /$ day were 1.2 times $(\mathrm{AHR}=$ 1.200; 95\%CI: 1.014-1.422) more likely to recover earlier compared to those who gained less than $8 \mathrm{~g} /$ $\mathrm{kg} /$ day. This is consistent with recommendations of the Ethiopian protocol for the management of severe acute malnutrition [9] as well as the sphere standard [10] which state that if children gain more than $8 \mathrm{~g} /$ $\mathrm{kg} /$ day starting from phase-2 (for wasted children) and after loss of edema (for edematous), the children can recover early within the acceptable minimum standard of days.

\section{Limitations of the study}

As the study was retrospective and based on secondary data, incomplete records were observed in some predictor variables. The research also failed to explore other parental socio-demographic and socioeconomic characteristics.

Table 5 Treatment outcomes of SAM, Bahir Dar, Northwest Ethiopia; October, 2012 to April, 2016

\begin{tabular}{lll}
\hline Variables & & Frequency (\%) \\
\hline Status at discharge & Cured & 208(51.9) \\
& Default & $143(35.7)$ \\
& Died & $17(4.2)$ \\
& Transfer & $27(6.7)$ \\
& Non-respondent & $6(1.5)$ \\
\hline
\end{tabular}




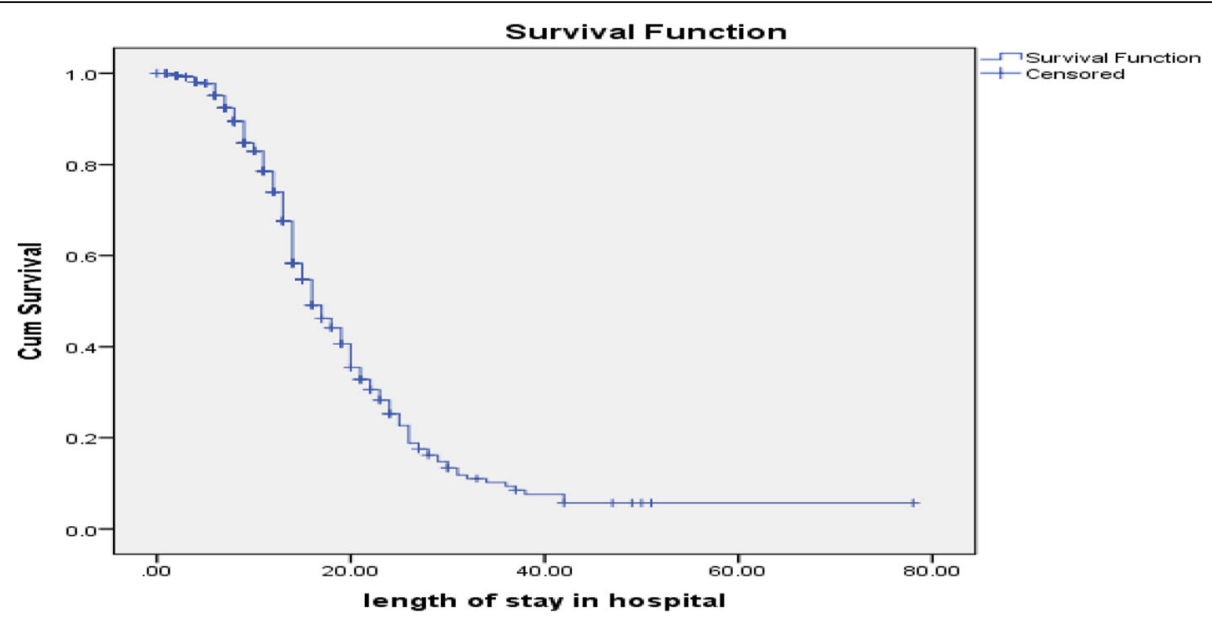

Fig. 1 Median recovery time among children with SAM managed at Felegehiwot referral hospital; October, 2012 to April, 2016

\section{Conclusions}

The median recovery time ranged in the accepted maximum international standards set for management of SAM. There were significant differences in the median nutritional recovery time between different groups of predictor variables. From the multivariate Cox proportional hazard regression, it was proved that children had a lower chance of recovering early when they had anemia, not provided plumpy nut, failed to enter phase 2 on day 10 and failed to gain more than $8 \mathrm{~g} / \mathrm{kg} /$ day.

Table 6 Kaplan-Meier outputs; recovery time from severe acute malnutrition among children, Bahir Dar, Northwest Ethiopia; October, 2012 to April, 2016

\begin{tabular}{|c|c|c|c|c|c|c|c|}
\hline \multirow[t]{2}{*}{ Characteristics } & & \multirow{2}{*}{$\begin{array}{l}\text { Number } \\
(\%)\end{array}$} & \multicolumn{5}{|c|}{ Median recovery time } \\
\hline & & & \multirow{2}{*}{$\begin{array}{l}\text { Estimate } \\
17.000\end{array}$} & \multicolumn{2}{|c|}{$95 \% \mathrm{Cl}$} & \multirow{2}{*}{$\frac{\text { Log rank } X^{2} \text {-value }}{7.800}$} & \multirow{2}{*}{$\frac{P \text { - value }}{.005}$} \\
\hline Cough & Yes & $101(49.3)$ & & 14.823 & 19.177 & & \\
\hline & No & 107(54.6) & 15.000 & 13.324 & 16.676 & & \\
\hline \multirow[t]{3}{*}{ HIV } & Yes & $9(42.9)$ & 27.000 & 12.824 & 41.176 & 7.798 & .020 \\
\hline & No & $90(58.1)$ & 17.000 & 14.097 & 19.903 & & \\
\hline & Not documented & 109(48.4) & 16.000 & 14.552 & 17.448 & & \\
\hline \multirow[t]{3}{*}{ TB } & Yes & 19(50.0) & 26.000 & 18.096 & 33.904 & 18.971 & .000 \\
\hline & No & 187(51.9) & 16.000 & 14.530 & 17.470 & & \\
\hline & Not documented & $2(66.7)$ & 9.000 & . & . & & \\
\hline \multirow[t]{2}{*}{ Anemia } & Yes & $125(60.1)$ & 18.000 & 16.099 & 19.901 & 33.085 & .000 \\
\hline & No & 83(39.9) & 14.000 & 12.157 & 15.843 & & \\
\hline \multirow[t]{2}{*}{ Fever $>39^{\circ} \mathrm{C}$} & Yes & $18(40.0)$ & 21.000 & 13.997 & 28.003 & 6.475 & .011 \\
\hline & No & 190(53.4) & 16.000 & 14.263 & 17.737 & & \\
\hline \multirow[t]{2}{*}{ Plumpy nut } & Yes & 180(82.6) & 14.000 & 13.033 & 14.967 & 34.617 & .000 \\
\hline & No & $28(15.3)$ & 28.000 & 23.301 & 32.699 & & \\
\hline \multirow[t]{2}{*}{ Fail to lose edema on day 4} & Yes & $26(31.3)$ & 24.000 & 16.471 & 31.529 & 4.103 & .043 \\
\hline & No & 182(57.2) & 16.000 & 14.450 & 17.550 & & \\
\hline \multirow[t]{2}{*}{ Edema still present on day 10} & Yes & 14(22.6) & 24.000 & 21.447 & 26.553 & 4.259 & .039 \\
\hline & No & 194(57.2) & 16.000 & 14.457 & 17.543 & & \\
\hline \multirow[t]{2}{*}{ Fail to enter phase 2 on day 10} & Yes & $20(15.5)$ & 30.000 & 20.971 & 39.029 & 46.114 & .000 \\
\hline & No & 188(69.1) & 14.000 & 13.061 & 14.939 & & \\
\hline \multirow[t]{2}{*}{ Failure to gain more than $5 \mathrm{~g} / \mathrm{kg} / \mathrm{d}$ for 3 successive days } & Yes & 28(19.3) & 26.000 & 23.262 & 28.738 & 28.002 & .000 \\
\hline & No & $180(70.3)$ & 15.000 & 14.018 & 15.982 & & \\
\hline
\end{tabular}


Table 7 Predictors of recovery time from severe acute malnutrition among children, Bahir Dar, Northwest Ethiopia; October, 2012 to April, 2016

\begin{tabular}{|c|c|c|c|c|c|c|}
\hline Covariate & & NO. at risk & Cured $(\mathrm{N}, \%)$ & Crude HR (95\% Cl) & P-value & Adjusted HR (95\% Cl) \\
\hline \multirow[t]{2}{*}{ Cough } & Yes & 205 & $101(49.3)$ & 1 & $.007^{* *}$ & $1.073(.799-1.442)$ \\
\hline & No & 196 & $107(54.6)$ & $1.455(1.106-1.912)$ & & \\
\hline \multirow[t]{2}{*}{ HIV } & Yes & 21 & $9(42.9)$ & 1 & $.013^{* *}$ & $1.263(.615-2.594)$ \\
\hline & No & 155 & $90(58.1)$ & $2.355(1.198-4.628)$ & & \\
\hline \multirow[t]{2}{*}{ Malaria } & Yes & 15 & $5(33.3)$ & 1 & $.121^{*}$ & $1.184(.504-2.779)$ \\
\hline & No & 382 & $202(52.9)$ & $1.904(.844-4.298)$ & & \\
\hline \multirow[t]{2}{*}{ TB } & Yes & 38 & 19(50.0) & 1 & $.000^{* *}$ & $1.540(.911-2.603)$ \\
\hline & No & 360 & 187(51.9) & 2.493(1.529-4.066) & & \\
\hline \multirow[t]{2}{*}{ Anemia } & Yes & 260 & $125(60.1)$ & 1 & $.000^{* *}$ & 1 \\
\hline & No & 140 & 83(39.9) & $1.713(1.292-2.272)$ & & $1.552(1.134-2.124)^{* *}$ \\
\hline \multirow[t]{2}{*}{ Fever $>39^{\circ} \mathrm{C}$} & Yes & 45 & $18(40.0)$ & 1 & $.015^{* *}$ & $1.354(.810-2.262)$ \\
\hline & No & 356 & 190(53.4) & $1.821(1.121-2.958)$ & & \\
\hline \multirow[t]{2}{*}{ Plumpy nut } & Yes & 218 & 180(82.6) & 3.008 (2.019-4.482) & $.000^{* *}$ & $2.063(1.356-3.139)^{* *}$ \\
\hline & No & 183 & $28(15.3)$ & 1 & & 1 \\
\hline \multirow[t]{2}{*}{ Fail to start to lose edema on day 4} & Yes & 17 & $6(35.3)$ & 1 & $052^{*}$ & 1.112(.648-1.906) \\
\hline & No & 69 & $40(57.2)$ & $1.505(.997-2.272)$ & & \\
\hline \multirow[t]{2}{*}{ Edema still present on day 10} & Yes & 14 & $4(22.6)$ & 1 & $.049^{* *}$ & $1.201(.605-2.382)$ \\
\hline & No & 72 & $42(57.2)$ & $1.727(1.003-2.974)$ & & \\
\hline \multirow[t]{2}{*}{ Fail to enter phase 2 on day 10} & Yes & 129 & 20(15.5) & 1 & $.000^{* *}$ & 1 \\
\hline & No & 272 & 188(69.1) & $4.216(2.647-6.714)$ & & $2.938(1.635-5.279)^{* *}$ \\
\hline \multirow[t]{2}{*}{ Failure to $>5 \mathrm{~g} / \mathrm{kg} / \mathrm{d}$ for 3 successive days } & Yes & 145 & $28(19.3)$ & 1 & $.000^{* *}$ & $1.229(.771-1.959)$ \\
\hline & No & 256 & 180(70.3) & $2.716(1.823-4.047)$ & & \\
\hline \multirow[t]{2}{*}{ Average weight gain } & $<8 \mathrm{~g} / \mathrm{kg} /$ day & 53 & $9(17.0)$ & 1 & $.025^{* *}$ & 1 \\
\hline & $>8 \mathrm{~g} / \mathrm{kg} /$ day & 348 & $199(57.2)$ & $1.190(1.022-1.386)$ & & $1.200(1.014-1.422)^{* *}$ \\
\hline
\end{tabular}

* Variables have $p$-value $\leq 0.2$ from binary analysis

** Statistically significant $(p$-value $<0.05)$ for both analyses

Health care providers (TFU care staff) are strongly advised to comply with inpatient SAM treatment and management protocols in early diagnosis and treatment of anemia, provision of plumpy nut, regular monitoring of weight gain and phase transition. To complement the limitations of this study, further study using prospective design should be conducted for better information including other factors not included under this study such as parental socio-demographic and socioeconomic characteristics, perception of care givers on severe undernutrition and therapeutic feeding programs.

\section{Abbreviations \\ AHR: Adjusted Hazard Ratio; Cl: Confidence interval; H R: Hazard ratio; MUAC: Mid-Upper -Arm Circumference; OTP: Outpatient Therapeutic Feeding Program; RUTF: Ready to use therapeutic food; SAM: Sever Acute Malnutrition; SD: Standard deviation; SPSS: Statistical Package for Social Sciences; TFU: Therapeutic feeding unit}

\section{Acknowledgements}

We would like to thank Bahir Dar Institute of Technology, Bahir Dar University for the financial support that made the study possible. Our special thanks go to Felegehiwot referral hospital administrators and staff for their cooperation.

\section{Availability of data and materials}

The datasets used and/or analyzed for the current study are available from the corresponding author on reasonable request.

\section{Authors' contributions}

DT participated in the conception of the study, acquisition of data, carried out the statistical analysis and drafted the manuscript. RP and TA reviewed all the drafts for intellectual content, participated in the interpretation of the findings, critical review and editing of all the manuscript drafts for scientific merit and depth. All authors read and approved the final manuscript.

\section{Ethics approval and consent to participate}

Ethical approval and clearance was obtained from Ethical Review Committee from Faculty of Chemical and Food Engineering, Bahir Dar Technology Institute prior to enrolment. Permission to conduct the study was obtained from regional health research bureau and Felegehiwot referral hospital prior to data collection.

\section{Consent for publication}

Not applicable

\section{Competing interests}

The authors declare that they have no competing interests. 


\section{Publisher's Note}

Springer Nature remains neutral with regard to jurisdictional claims in published maps and institutional affiliations.

\section{Author details}

'Department of Applied Human Nutrition, Bahir Dar Institute of Technology, Bahir Dar University, Bahir Dar, Ethiopia. ${ }^{2}$ Department of Epidemiology and Biostatistics, Institute of Public Health, College of Medicine and Health sciences, University of Gondar, Gondar, Ethiopia.

\section{Received: 5 April 2017 Accepted: 3 April 2018}

Published online: 10 April 2018

\section{References}

1. Joosten KF, Hulst JM. Prevalence of malnutrition in pediatric hospital patients. Curr Opin Pediatr. 2008;20(5):590-6.

2. Kramer CV, Allen S. Malnutrition in developing countries. Paediatr Child Health. 2015;25(9):422-7.

3. Müller O, Krawinkel M. Malnutrition and health in developing countries. Can Med Assoc J. 2005;173(3):279-86.

4. WHO UNICEF, WFP. Community-based management of severe acute malnutrition. Geneva. 2007.

5. Hobbs B, Bush A, Shaikh B, Azmat S, Mazhar A, Solter S, et al. Acute malnutrition: an everyday emergency. A 10-point plan for tackling acute malnutrition in under-fives. JPMA J Pak Med Assoc. 2013;63(4 Suppl 3):S67-72.

6. Black RE, Cousens S, Johnson HL, Lawn JE, Rudan I, Bassani DG, et al. Child Health Epidemiology Reference Group of WHO and UNICEF. Global, regional, and national causes of child mortality in 2008: a systematic analysis. Lancet. 2010;375(9730):1969-87.

7. Black RE, Victora C, Walker SP, Bhutta ZA, Christian P, de Onis M, et al. Maternal and Child Nutrition Study Group. Maternal and child undernutrition and overweight in low-income and middle-income countries. Lancet. 2013;382(9890): 427-51.

8. World Health Assembly. Global Nutrition Targets 2025. 2012.

9. Federal Misnstry of Health. Protocol for the Management of Severe Acute Malnutrition. Ethiopia. 2007.

10. The Sphere Handbook: Humanitarian charter and minimum standards in humanitarian response. The Sphere Project, at http://www.sphereproject. org/handbook; 2011.

11. WHO, UNICEF. Child growth standards and the identification of severe acute malnutrition in infants and children: joint statement by the World Health Organization and the United Nations Children's fund. 2009.

12. Gebremichael M, Bezabih AM, Tsadik M. Treatment outcomes and associated risk factors of severely malnourished under five children admitted to therapeutic feeding centers of Mekelle City, northern Ethiopia. Open Access Library J. 2014; (04):1.

13. Munthali T, Jacobs C, Sitali L, Dambe R, Michelo C. Mortality and morbidity patterns in under-five children with severe acute malnutrition (SAM) in Zambia: a five-year retrospective review of hospital-based records (2009-2013). Arch Public Health. 2015;73(1):23.

14. Yebyo HG, Kendall C, Nigusse D, Lemma W. Outpatient therapeutic feeding program outcomes and determinants in treatment of severe acute malnutrition in Tigray, northern Ethiopia: a retrospective cohort study. PLoS One. 2013;8(6):e65840.

15. Shanka NA, Lemma S, Abyu DM. Recovery rate and determinants in treatment of children with severe acute malnutrition using outpatient therapeutic feeding program in Kamba District, South West Ethiopia. J Nutr Disord Ther. 2015;5:155. https:/doi.org/10.4172/2161-0509.1000155.

16. Gebremichael DY. Predictors of nutritional recovery time and survival status among children with severe acute malnutrition who have been managed in therapeutic feeding centers, southern Ethiopia: retrospective cohort study. BMC Public Health. 2015;15(1):1

17. Savadogo LGB, Zoetaba I, Illboudo B, Kinda M, Donnen P. Impact of anemia on mortality and nutritional recovery among hospitalized severely malnourished children in Burkina Faso. Open J Pediatr. 2014;2014:115-20.

18. Lenters LM, Wazny K, Webb P, Ahmed T, Bhutta ZA. Treatment of severe and moderate acute malnutrition in low-and middle-income settings: a systematic review, meta-analysis and Delphi process. BMC Public Health. 2013;13(3):1.

\section{Ready to submit your research? Choose BMC and benefit from:}

- fast, convenient online submission

- thorough peer review by experienced researchers in your field

- rapid publication on acceptance

- support for research data, including large and complex data types

- gold Open Access which fosters wider collaboration and increased citations

- maximum visibility for your research: over $100 \mathrm{M}$ website views per year

At BMC, research is always in progress.

Learn more biomedcentral.com/submissions 